\title{
Steady-state dissolution kinetics of goethite in the presence of desferrioxamine B and oxalate ligands: implications for the microbial acquisition of iron
}

\author{
Sing-Foong Cheah ${ }^{\mathrm{a}}$, Stephan M. Kraemer ${ }^{\mathrm{b}}$, Javiera Cervini-Silva ${ }^{\mathrm{a}}$, Garrison Sposito ${ }^{\mathrm{a}, *}$ \\ ${ }^{a}$ Division of Ecosystem Sciences, University of California, Berkeley, CA 94720-3110, USA \\ ${ }^{\mathrm{b}}$ Institute of Terrestrial Ecology, ETH-Zürich, CH-8952, Schlieren, Switzerland
}

Received 12 September 2001; accepted 26 November 2002

\begin{abstract}
This paper reports an investigation of the effects of a trihydroxamate siderophore, desferrioxamine B (DFO-B), and a common biological ligand, oxalate, on the steady-state dissolution of goethite at $\mathrm{pH} 5$ and $25{ }^{\circ} \mathrm{C}$. The main goal of our study was to quantify the adsorption of the ligands and the dissolution of goethite they promote in a two-ligand system. In systems with one ligand only, the adsorption of oxalate and DFO-B each followed an L-type isotherm. The surface excess of oxalate was approximately $40 \mathrm{mmol} \mathrm{kg}^{-1}$ at solution concentrations above $80 \mu \mathrm{M}$, whereas the surface excess of DFO-B was only 1.2 mmol kg-1 at $80 \mu \mathrm{M}$ solution concentration. In the two-ligand systems, oxalate decreased DFO-B adsorption quite significantly, but not vice versa. For example, in solutions containing $40 \mu \mathrm{M}$ DFO-B and $40 \mu \mathrm{M}$ oxalate, $30 \%$ of the DFO-B adsorbed in the absence of oxalate was displaced. The mass-normalized dissolution rate of goethite in the presence of DFO-B alone increased as the surface excess of the ligand increased, suggesting a ligand-promoted dissolution mechanism. In systems containing oxalate only, mass-normalized goethite dissolution rates were very low at concentrations below $200 \mu \mathrm{M}$, despite maximal adsorption of the ligand. At higher oxalate concentrations (up to $8 \mathrm{mM}$ ), the steady-state dissolution rate continued to increase, even though the surface excess of adsorbed ligand was essentially constant. Chemical affinity calculations and dissolution experiments with variation of the reactor flow rate showed that far-from-equilibrium conditions did not obtain in systems containing oxalate at concentrations below $5 \mathrm{mM}$. The dissolution rate in the presence of DFO-B at solution concentrations between 1 and $80 \mu \mathrm{M}$ was approximately doubled when oxalate was also present at $40 \mu \mathrm{M}$ solution concentration. The dissolution rate in the presence of oxalate at solution concentrations between 0 and $200 \mu \mathrm{M}$ was increased by more than an order of magnitude when DFO-B was also present at $40 \mu \mathrm{M}$ solution concentration. Chemical affinity calculations showed that, in systems containing DFO-B, goethite dissolution was always under far-from-equilibrium conditions, irrespective of the presence of oxalate. These results were described quantitatively by a model rate law containing a term proportional to the surface excess of DFO-B and a term proportional to that of oxalate, with both surface excesses being determined in the twoligand system. The pseudo first-order rate coefficient in the DFO-B term has the same value as measured for goethite dissolution in the presence of DFO-B only, while the rate coefficient in the oxalate term must be measured in the two-ligand system, since it is only in this system that far-from-equilibrium conditions obtain. These latter conditions do not exist in the system containing oxalate only, but they do exist in the DFO-B/oxalate system because the siderophore is able to remove Fe(III) from all $\mathrm{Fe}$-oxalate complexes rapidly, leaving the uncomplexed oxalate ligand in solution free to react again with the goethite
\end{abstract}

* Corresponding author.

E-mail address: gsposito@nature.berkeley.edu (G. Sposito). 
surface. This synergy observed in the two-ligand system implies that the production of modest quantities of siderophore in the presence of very low concentrations of oxalate would be an extremely effective mechanism for the microbially induced release of Fe from goethite.

(C) 2003 Published by Elsevier Science B.V.

Keywords: Iron oxyhydroxides; Siderophores; Adsorption; Microbial dissolution; Geomicrobiology

\section{Introduction}

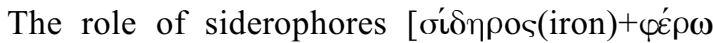
(carry)] in the acquisition of iron by fungi and bacteria has long been appreciated (Neilands, 1974; Cornell and Schwertmann, 1996; Albrecht-Gary and Crumbliss, 1998), but little quantitative understanding of the biogeochemistry of these microbial compounds is available. Kalinowski et al. (2000) have reviewed the few extant studies of siderophore-promoted mineral dissolution, noting particularly the unexpectedly modest enhancement of dissolution rates that siderophores produce and the existence of a "saturation effect" (plateau in the dissolution rate as a function of ligand concentration) for dissolution promoted by trihydroxamate siderophores. They concluded with a call for "careful, controlled experiments in chemical reactors" to improve understanding of siderophore biogeochemistry.

In a pioneering experiment with goethite $(\alpha-$ $\mathrm{FeOOH}$ ), Watteau and Berthelin (1994) observed the release of twice as much $\mathrm{Fe}$ in the presence of $126 \mu \mathrm{M}$ desferrioxamine B (DFO-B), a common trihydroxamate siderophore (Crumbliss, 1991), as in the presence of $\mathrm{HCl}$ at $\mathrm{pH} 3$ over a 28-day reaction. A $3 \mathrm{mM}$ mixture of oxalic, malic, and citric acid at $\mathrm{pH} 3$ released almost three times as much $\mathrm{Fe}$ as did $\mathrm{HCl}$ during the same period. However, on a per-mole basis, the siderophore was nearly 20 times more effective than were the aliphatic acids at releasing $\mathrm{Fe}$ from goethite. Similar data were obtained with other Febearing minerals (Watteau and Berthelin, 1994).

Kraemer et al. (1999) also observed enhanced Fe release from goethite in the presence of $240 \mu \mathrm{M}$ DFO$\mathrm{B}$ at $\mathrm{pH} 6.5$, concluding, in agreement with Holmén and Casey $(1996,1998)$ and Kalinowski et al. (2000), that coordination of the siderophore to an $\mathrm{Fe}(\mathrm{III})$ center at the mineral surface is a precursor to the dissolution process. Cocozza et al. (2001) compared the temper- ature dependence of goethite dissolution at $\mathrm{pH} 6.5$ in the presence of $240 \mu \mathrm{M}$ DFO-B with that of $\mathrm{Fe}^{3+}$ complexation by the siderophore in aqueous solution, concluding that DFO-B coordinates with only a single hydroxamate group when binding to an $\mathrm{Fe}(\mathrm{III})$ center on the goethite surface, a possibility suggested previously by Holmén and Casey $(1996,1998)$.

Watteau and Berthelin (1994) noted that aliphatic acids at submillimolar concentrations typical for soils usually promoted greater $\mathrm{Fe}$ release from minerals than did DFO-B at typical micromolar concentrations. They speculated that the presence of both types of organic ligand could result in selective strategies for mobilizing Fe from minerals under a variety of soil conditions. In this paper, we take up the issue of combined ligand effects in presenting the results of adsorption and steady-state dissolution experiments involving goethite in the presence of DFO-B and the ubiquitous biological ligand, oxalate (Gadd, 2000). Our objective was to quantify the dissolution kinetics of goethite at varying concentrations of DFO-B, oxalate, and the two ligands in combination, so as to gain insight into their possible combined role in the microbial acquisition of Fe.

\section{Materials and methods}

\subsection{Materials}

The sample of desferrioxamine $\mathrm{B}$ used was the mesylate salt $\left[\mathrm{C}_{25} \mathrm{H}_{46} \mathrm{~N}_{5} \mathrm{O}_{8} \mathrm{NH}_{3}^{+}\left(\mathrm{CH}_{3} \mathrm{SO}_{3}^{-}\right)\right]$, obtained initially from Sigma, but primarily from a sample produced by Ciba-Geigy (Desferal ${ }^{\circledR}$ ) that was received as a gift from the Salutar Corporation. The unlabeled sample of oxalic acid $\left(\mathrm{C}_{2} \mathrm{H}_{4} \mathrm{O}_{2}\right)$ used was obtained from Aldrich (Cat. No. 24, 117-2; 99+\%), whereas ${ }^{14} \mathrm{C}$-labeled oxalic acid was obtained from Sigma Radiochemicals [(Cat. No. 31, 391-2, Lot No. 
18H9466; specific activity $7.1 \mathrm{mCi} \mathrm{mmol}{ }^{-1}(\mathrm{Ci}=$ curie)].

Solutions containing desferrioxamine B mesylate, oxalic acid, ${ }^{14} \mathrm{C}$-labeled oxalic acid, sodium perchlorate (GFS, ACS grade), MOPS buffer (3-[N-Morpholino]propanesulfonic acid; Sigma), MES buffer (2-[NMorpholino] ethanesulfonic acid; Sigma), sodium hydroxide (Baker Analyzed Reagent Grade), perchloric acid (Fisher, Optima grade), Fe(III) perchlorate hexahydrate (GFS, ACS grade), or Fe ICP standard solution (Ultra Scientific) were prepared with highpurity $18 \mathrm{M} \Omega \mathrm{cm}^{-1}$ water (Milli-Q Plus, Millipore). The scintillation cocktail used for ${ }^{14} \mathrm{C}$ analysis (Scintiverse) was obtained from Fisher.

Goethite $(\alpha-\mathrm{FeOOH})$ was synthesized using a method described by Schwertmann and Cornell (1991). Briefly, $180 \mathrm{ml}$ of $5 \mathrm{M} \mathrm{KOH}$ solution were added rapidly with stirring to $100 \mathrm{ml}$ of $1 \mathrm{M} \mathrm{Fe}\left(\mathrm{NO}_{3}\right)_{3}$ solution in a 21 polyethylene flask. The resulting suspension was then brought to 21 total volume with high-purity $18 \mathrm{M} \Omega \mathrm{cm}^{-1}$ water and heated at $70{ }^{\circ} \mathrm{C}$ for $60 \mathrm{~h}$. The precipitated product was stored in suspension for a few months, centrifuged, washed with high-purity water, then freeze-dried. Powder Xray diffraction and transmission electron microscopy confirmed that the synthesized solid was goethite. Its specific surface area (static BET method) was $35 \pm 3$ $\mathrm{m}^{2} \mathrm{~g}^{-1}$. Prior to the adsorption and dissolution experiments, a goethite stock suspension was prepared by sonicating a mixture of the freeze-dried precipitate with the background electrolyte solution for $1 \mathrm{~min}$.

\subsection{Dissolution experiments}

Continuous-flow stirred tank reactors (Nagy et al., 1991; Kraemer and Hering, 1997) were used in the goethite dissolution experiments. The reactors were obtained from Cole-Parmer (Cat. No. E-02910-41), the cap and bottom being made with Delrin ${ }^{\circledR}$, while the main reactor body was machined in Berkeley with Plexiglass ${ }^{\circledR}$. The volume of the reactors was determined by carefully filling them with water (with a $0.025 \mu \mathrm{m}$ filter in place) and measuring the additional mass. The median volume of the four reactors was $69.4 \pm 0.3 \mathrm{ml}$.

The reactors were immersed in a constant-temperature water bath at $25{ }^{\circ} \mathrm{C}$, with the entire apparatus wrapped in $\mathrm{Al}$ foil to exclude light during the experi- ments. A $0.025 \mu \mathrm{m}$ mixed cellulose-acetate filter (Millipore) was placed at the outflow of each reactor to contain the goethite sample within it. The goethite concentration in the reactor was $10.0 \mathrm{~g} \mathrm{l}^{-1}$. The goethite slurry was mixed by a suspended magnetic stirrer (i.e., one that does not contact the bottom of the reactor). The stirring speed, monitored using a stroboscope, was maintained at $500 \mathrm{rpm}$. The flow rate in the reactors was controlled using a variable-speed peristaltic pump (Masterfex ${ }^{\circledR}$ ) and was determined daily by collecting effluent over a fixed period of time and then dividing the volume of the effluent by the collection time. Pump tubing was replaced every $2-3$ weeks, with no data collected for 2 days after replacement. Care was taken to ensure that there were no air bubbles trapped in the pump tubing or in the tubing connecting bottles containing the influent solutions to the reactors.

The composition of the influent solutions was 10 $\mathrm{mM} \mathrm{NaClO}_{4}$ at $\mathrm{pH} 5$ mixed with oxalate $(0-8000 \mu \mathrm{M})$ and/or DFO-B $(0-80 \mu \mathrm{M})$. All experiments were conducted with MOPS buffer, except for those involving oxalate alone at concentrations between 200 and $8000 \mu \mathrm{M}$, which were conducted with MES buffer. Kraemer et al. (1999) have shown that the use of MOPS buffer has no significant effect on the dissolution rate of goethite. Yu et al. (1997) and Soares et al. (1999) also have found that MOPS and MES buffers are noncomplexing ligands with trace metal ions. Effluent samples were collected daily, with one portion used for $\mathrm{pH}$ measurements. A second portion was stored in a refrigerator to be used weekly for measurement of total dissolved $\mathrm{Fe}$ concentration by inductively coupled plasma-atomic emission spectrometry (ICP-AES).

The mass-normalized steady-state dissolution rate of goethite was calculated as:

$R=[\mathrm{Fe}]_{\mathrm{eff}} \frac{q}{m}$

where $[\mathrm{Fe}]_{\text {eff }}$ is the total dissolved Fe concentration in the effluent $(\mu \mathrm{M})$ under steady-state conditions, $q$ is the effluent flow rate $\left(\mathrm{ml} \mathrm{h}^{-1}\right)$, and $m$ is the mass of goethite in the reactor $(\mathrm{g})$. The resulting units of $R$ are then $\mu \mathrm{mol} \mathrm{kg} \mathrm{kg}^{-1} \mathrm{~h}^{-1}$. The standard deviation of $R$ values $(\Delta R)$ was estimated as:

$\Delta R=R\left[\left(\frac{\Delta[\mathrm{Fe}]_{\mathrm{eff}}}{[\mathrm{Fe}]_{\mathrm{eff}}}\right)^{2}+\left(\frac{\Delta q}{q}\right)^{2}+\left(\frac{\Delta m}{m}\right)^{2}\right]^{1 / 2}$ 
where $\Delta[\mathrm{Fe}]_{\mathrm{eff}}$ is the standard deviation of $[\mathrm{Fe}]_{\mathrm{eff}}$, etc. The minimum detectable $[\mathrm{Fe}]_{\text {eff }}$ was $0.04 \mu \mathrm{M}$ and the smallest dissolution rate measurable in our experiments was about $0.1 \mu \mathrm{mol} \mathrm{kg}{ }^{-1} \mathrm{~h}^{-1}$.

\subsection{Adsorption experiments}

Adsorption of the organic ligands on goethite was investigated in batch mode in $10 \mathrm{mM} \mathrm{NaClO}_{4}$ and 5 $\mathrm{mM}$ MOPS buffer, with samples open to the atmosphere at ambient temperature. A stock suspension containing $30.0 \mathrm{~g}^{-1}$ goethite was prepared and, for each adsorption experiment, $5 \mathrm{ml}$ of the suspension and predetermined volumes of electrolyte and acid/ base were placed in $30 \mathrm{ml}$ amber HDPE bottles. Aliquots of stock solutions containing DFO-B (2 $\mathrm{mM})$, oxalic acid $(4 \mathrm{mM})$ and/or ${ }^{14} \mathrm{C}$ labeled oxalic acid $(1 \mu \mathrm{Ci} / \mathrm{ml} ; 133 \mu \mathrm{M})$ were then added to achieve the desired solution composition. The labeled oxalic acid aliquot was always added immediately after the nonlabeled oxalic acid. The order in which DFO-B and nonlabeled oxalate were added was randomized from sample to sample. The total volume of each sample was $15 \mathrm{ml}$, yielding solids concentration of $10.0 \mathrm{~g} \mathrm{l}^{-1}$. The samples were placed on a rotator for 1 $\mathrm{h}$ to equilibrate them before being filtered. The filtration process required about $20 \mathrm{~min}$, so the actual equilibration time of a sample was nearly $100 \mathrm{~min}$. This reaction time was optimized so that dissolved $\mathrm{Fe}$ would not be a substantial part of the equilibrated solution composition $(<10 \mu \mathrm{M})$. Solution $\mathrm{pH}$ was measured immediately after all components were added ( $\mathrm{pH}$ of the slurry) and after filtration ( $\mathrm{pH}$ of the filtrate). There was no significant change of $\mathrm{pH}$ in all cases, the average sample $\mathrm{pH}$ being $5.06 \pm 0.07$.

The equilibrated samples were filtered with either a $0.05 \mu \mathrm{m}$ (Millipore) mixed cellulose ester membrane filter or a $0.2 \mu \mathrm{m}$ Nalgene ${ }^{\circledR}$ surfactant-free celluloseacetate disposable syringe-filter, the latter being found to be just as effective as the $0.05 \mu \mathrm{m}$ filter for our sample of goethite. Experiments with (goethite-free) blank solutions were conducted to check for loss of DFO-B or oxalic acid to container walls or to the filter. Because of the filter loss, which was typically on the order of a few percent of the ligand concentration in the filtrate, it was found prudent to presaturate the filter with the sample solution, then discard the first few milliliters of filtrate. For samples filtered with a $0.05 \mu \mathrm{m}$ mixed cellulose ester membrane filter, the first $2 \mathrm{ml}$ of filtrate was discarded; for samples filtered with a $0.2 \mu \mathrm{m}$ Nalgene brand surfactant-free cellulose-acetate disposable syringe-filter, the first $6 \mathrm{ml}$ of filtrate was discarded. Experiments following this protocol showed negligible loss of DFO-B and oxalic acid in blank solutions.

The surface excess of the analyte (DFO-B or oxalic acid) was calculated by dividing the concentration loss (initial concentration minus the total ligand concentration in the filtrate) by the solids concentration. Errors in adsorbed concentration were estimated based on equating the sample coefficient of variation to the square root of the sum of squares of the coefficients of variation of constituent quantities in the definition of the surface excess, similarly to Eq. (2).

\subsection{Analytical methods}

The concentration of DFO-B in the filtrate from an adsorption experiment was analyzed with a Shimadzu UV-160 spectrophotometer at $439 \mathrm{~nm}$ as the Fe-DFO$\mathrm{B}$ complex in the presence of excess $\mathrm{Fe}$ (Solinas, 1994; Cocozza et al., 2001). All spectrophotometric measurements were conducted within $2 \mathrm{~h}$ after filtration. Standards and filtrates were acidified to $\mathrm{pH} 1.5-$ 1.7 by addition of $8 \mu 1$ of $67 \%$ perchloric acid. Then $0.1 \mathrm{ml}$ of $9.4 \mathrm{mM} \mathrm{Fe}\left(\mathrm{ClO}_{4}\right)_{3}$ solution was added to one aliquot of a split filtrate sample to achieve an $\mathrm{Fe}$ concentration of $302 \mu \mathrm{M}$. According to speciation calculations performed with MINEQL+ (Schecher and McAvoy, 1998), this Fe concentration is in excess of that required to complex all DFO-B in any filtrate analyzed. Corresponding ligand-free blank solutions, containing the background electrolyte solution, MOPS buffer, and $302 \mu \mathrm{M} \mathrm{Fe}$, also were acidified to $\mathrm{pH} 1.5-$ 1.7. Therefore, subtraction of the absorbance of a blank solution from that of a sample aliquot with $\mathrm{Fe}$ added yields the absorbance of the total siderophore in the sample (i.e., free siderophore ligands plus siderophore complexed with any $\mathrm{Fe}$ released). The net absorbance of the blank-corrected sample to which $\mathrm{Fe}$ was not added was attributed to $\mathrm{Fe}$ released by goethite dissolution during the adsorption experiments.

Samples containing both oxalic acid and DFO-B exhibited an additional absorbance peak at $288 \mathrm{~nm}$. Deconvolution of the peaks at 288 and $439 \mathrm{~nm}$ was 
necessary to determine the concentration of DFO-B accurately. This was accomplished using measurements of the molar absorptivity of oxalate and DFO$\mathrm{B}$ at both wavelengths, obtained for a series of standards of each ligand in solution at $\mathrm{pH} 1.5-1.7$ with the background electrolyte, MOPS buffer, and $302 \mu \mathrm{M}$ Fe. Coupled linear equations relating the observed absorbance for an oxalate-DFO-B solution to the four molar absorptivities and the concentration of each ligand were then solved to calculate the DFO-B concentration in a sample.

Quantitation of ${ }^{14} \mathrm{C}$-labeled oxalic acid was used to determine the concentration of oxalic acid both before the addition of solid and after filtration in the adsorption experiments. Standards containing 0.1, 0.01, $0.001,0.0001$, and $0 \mu \mathrm{Ci}$ were prepared. One milliliter of filtrate or standard solution was mixed with $14 \mathrm{ml}$ of scintillation cocktail (Scintiverse, Fisher) and counted on a Beckman LS9000 Scintillation counter. For each adsorption sample, $0.1 \mu \mathrm{Ci}$ of ${ }^{14} \mathrm{C}$-labeled oxalic acid was added. If there is no preferential adsorption of radiolabeled vs. nonlabeled oxalic acid, the ratio of residue radioactivity in the filtrate to the total radioactivity added initially represents the fraction of oxalic acid not adsorbed. Iron concentrations were determined by ICP-AES (Thermo Jarrel-Ash) using the emission line at $238.2 \mathrm{~nm}$. Proton activity was measured with a Ross combination electrode calibrated with buffers at $\mathrm{pH} 4.0,7.0$, and 10.0.

\section{Results and discussion}

\subsection{Oxalate and DFO-B adsorption}

Fig. 1 shows adsorption isotherms at $\mathrm{pH} 5$ for oxalate and for DFO-B on goethite in $10 \mathrm{mM} \mathrm{NaClO}_{4}$ background electrolyte solution. Oxalate (Fig. 1a) exhibited an L-type isotherm (Sposito, 1989) that was quantified by regression analysis using a linear form of the Langmuir equation:

$n=n_{\max }-K_{\mathrm{ads}} \frac{n}{[]}$

where $n$ is surface excess, [ ] is adsorptive concentration, $n_{\max }$ is an adjustable "capacity" parameter, and $K_{\text {ads }}$ is an adjustable "affinity" parameter (Fig. $1 b)$. The maximum surface excess $\left(n_{\max }\right)$ was equal to (a)

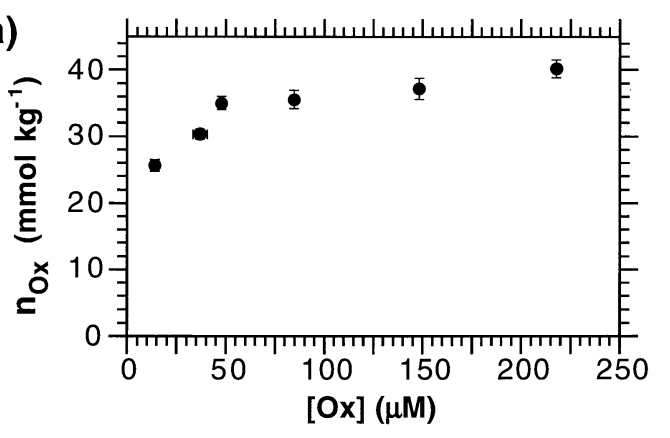

(b)

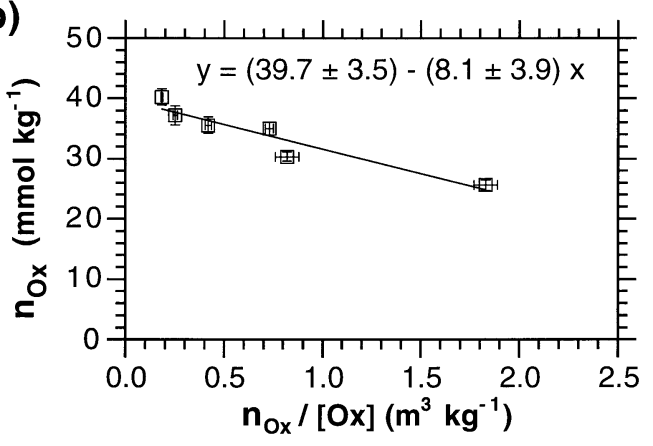

(c)

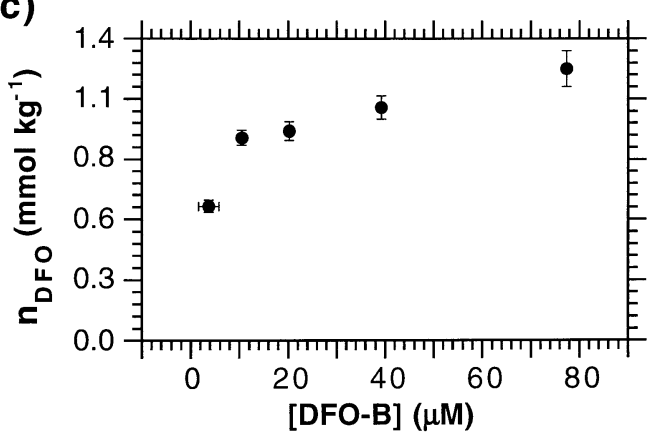

Fig. 1. (a) Adsorption isotherm for oxalate on goethite. (b) Linearized Langmuir equation fit of the oxalate adsorption data in (a) using Eq. (3). The line through the data is a least-squares adjustment $\left[y \equiv n\left(\mathrm{mmol} \mathrm{kg} \mathrm{kg}^{-1}\right), x \equiv n /[] \quad\left(\mathrm{m}^{3} \mathrm{~kg}^{-1}\right)\right]$. (c) Adsorption isotherm for DFO-B on goethite $\left(n_{\max }=1.23 \pm 0.18\right.$ $\left.\mathrm{mmol} \mathrm{kg}{ }^{-1}, K_{\text {ads }}=3.7 \pm 2.1 \mu \mathrm{M}\right)$. Solution concentrations are those measured after $100 \mathrm{~min}$ in a suspension containing $10 \mathrm{mM} \mathrm{NaClO}_{4}$, $10 \mathrm{~g}^{-1}$ goethite, and $5 \mathrm{mM}$ MOPS buffer at $\mathrm{pH}$ 5. Error bars for the surface excess were calculated as described in Section 2.3, whereas those for the solution concentration reflect the range of values measured in duplicate experiments.

$40 \pm 4 \mathrm{mmol} \mathrm{kg}^{-1}\left(1.1 \pm 0.1 \mu \mathrm{mol} \mathrm{m}{ }^{-2}\right)$, which is in agreement with previous measurements of oxalate adsorption by goethite at $\mathrm{pH} 5$ reported by Zinder et al. (1986), Djafer et al. (1991), Mesuere and Fish 


\section{ARTICLE IN PRESS}

(a)
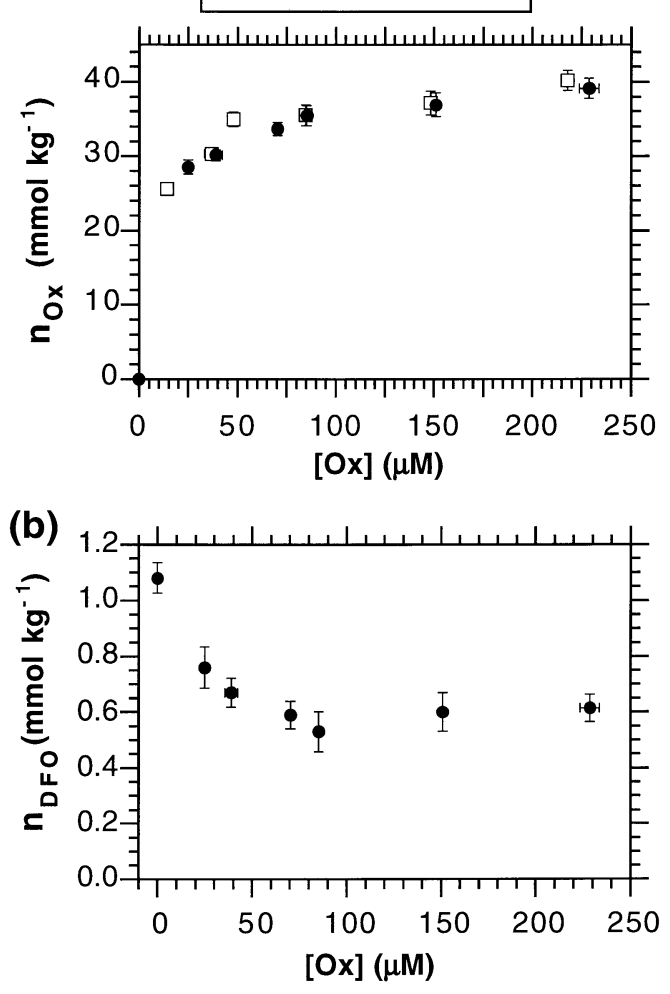

Fig. 2. Adsorption isotherms for (a) oxalate and (b) DFO-B in the presence of varying oxalate concentration and $40 \mu \mathrm{M}$ DFO-B. Solution conditions and error estimates are the same as for Fig. 1.

(1992), and Eick et al. (1999). Adsorption of DFO-B also followed an L-type isotherm (Fig. 1c), with a Langmuir equation fit indicating a maximum surface excess $\left(n_{\max }\right)$ of $1.2 \pm 0.2 \mathrm{mmol} \mathrm{kg}^{-1}(34 \pm 6 \mathrm{nmol}$ $\mathrm{m}^{-2}$ ), in agreement with the results of Kraemer et al. (1999). They attributed this rather low $n_{\max }$ value both to repulsion of the cationic DFO-B $\left(\mathrm{p} K_{\mathrm{a}}=8.5\right)$ by the positively charged goethite surface [i.e.p. $\approx 8.4(\mathrm{Dja}-$ fer et al., 1991); i.e.p. is the $\mathrm{pH}$ value at which a particle exhibits zero electrokinetic mobility (Sposito, 1998)], and to steric hindrance encountered by the siderophore while attempting to complex an $\mathrm{Fe}(\mathrm{III})$ center in the mineral. Cocozza et al. (2001) have hypothesized that both hydrophobic and stereochemical effects limit the siderophore to using just one of its three hydroxamate groups for complexing these Fe(III) centers.
Figs. 2 and 3 show adsorption isotherms at $\mathrm{pH} 5$ for oxalate in the presence of $40 \mu \mathrm{M}$ DFO-B and for DFO$\mathrm{B}$ in the presence of $36 \mu \mathrm{M}$ oxalate. As would be expected from the 30-fold disparity in surface excess (Fig. 1), oxalate adsorption was not affected by the presence of DFO-B (Fig. 2a), whereas the surface excess of DFO-B was reduced significantly as the concentration of oxalate was increased (Fig. 2b). Similarly, DFO-B adsorption was strongly affected by the presence of $36 \mu \mathrm{M}$ oxalate (Fig. 3a), whereas the surface excess of oxalate was essentially unaffected by increasing concentrations of DFO-B, up to $80 \mu \mathrm{M}$ (Fig. 3b). Moreover, the DFO-B adsorption isotherm in the presence of oxalate shifted from L-type to S-type (Fig. 3a), which indicates competition between oxalate and DFO-B for adsorption sites (Sposito, 1989).

Djafer et al. (1991) observed the i.e.p. of goethite to drop from 8.4 in $1 \mathrm{mM} \mathrm{KNO}_{3}$ without oxalate to
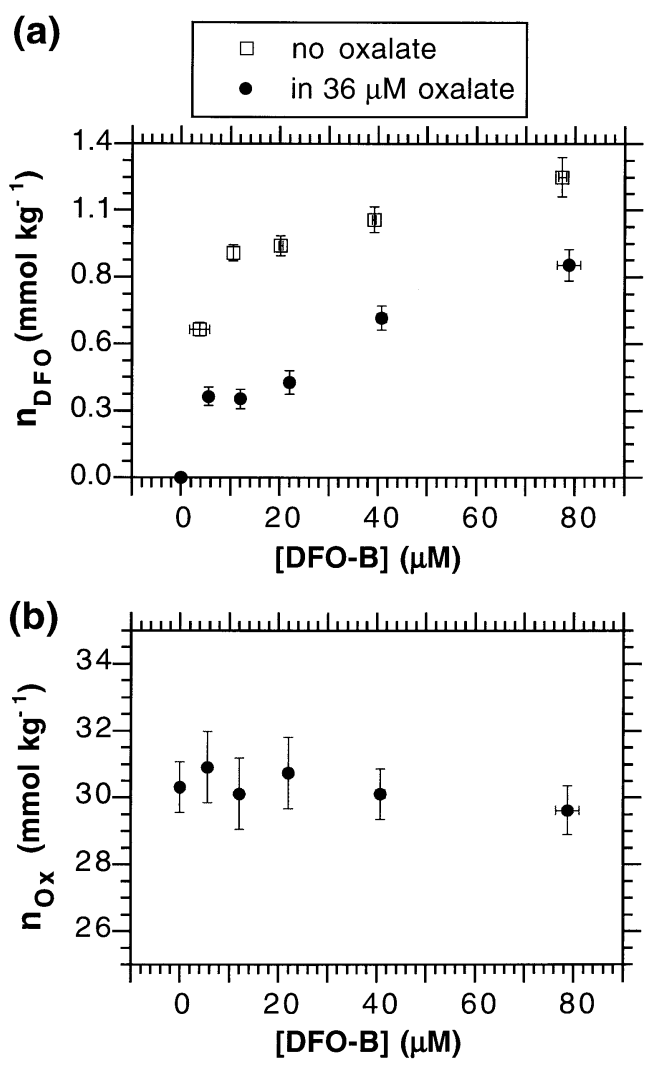

Fig. 3. Adsorption isotherms for (a) DFO-B and (b) oxalate in the presence of varying DFO-B concentration and $36 \mu \mathrm{M}$ oxalate. Solution conditions and error estimates are the same as for Fig. 1. 
7.5 or 7.0 in the presence of 10 or $100 \mu \mathrm{M}$ oxalate, respectively. Oxalate adsorption thus lowers the surface charge on goethite, which then should facilitate adsorption of the cationic DFO-B ligand. However, the data in Figs. $2 \mathrm{~b}$ and $3 \mathrm{a}$ indicate that, despite this expected enhancement, oxalate actually interfered with the adsorption of DFO-B on goethite, even when the solution concentration of DFO-B was twice that of the oxalate.

In summary, our isotherm data indicate that oxalate adsorption by goethite at $\mathrm{pH} 5$ is maximal for solution concentrations above $250 \mu \mathrm{M}$ (Fig. 1a), and is much greater than DFO-B adsorption under the same conditions. Oxalate also interferes effectively with DFO$B$ adsorption. These results suggest that the goethite surface sites available to DFO-B are a subset of those available to oxalate. It is possible that the much larger size of DFO-B $\left(M_{\mathrm{r}}=561.7 \mathrm{Da}\right)$ relative to oxalate $\left(M_{\mathrm{r}}=56 \mathrm{Da}\right)$ hinders DFO-B binding to the goethite surface.

\subsection{Goethite dissolution kinetics}

Fig. 4 shows graphs of the mass-normalized dissolution rate of goethite (filled circles, see also Table 1) and the surface excess of DFO-B (open triangles) both plotted against DFO-B concentration. The approximate congruence of the two graphs and the close similarity of our graph of dissolution rate vs. concentration to that reported by Liermann et al. (2000) for DFO-B-promoted hornblende dissolution lend credence to an interpretation of the data as evidence for DFO-B-promoted goethite dissolution kinetics. A pseudo first-order rate coefficient (units of $\mathrm{h}^{-1}$ ) for ligand-promoted dissolution is conventionally calculated as the ratio of the mass-normalized dissolution rate to the surface excess (Zinder et al., 1986). The data in Fig. 4a at DFO-B concentrations of 20, 40, and 80 $\mu \mathrm{M}$ yield an average value of $0.015 \pm 0.003 \mathrm{~h}^{-1}$ for this rate coefficient, in agreement with pseudo firstorder rate coefficients that can be calculated using kinetics data reported by Watteau and Berthelin (1994) and Kraemer et al. (1999) for DFO-B-promoted dissolution of goethite at circumneutral $\mathrm{pH}$.

The above calculation is made under the assumption that the proton-promoted dissolution rate of goethite under our experimental conditions is negligible. This assumption can be tested statistically by
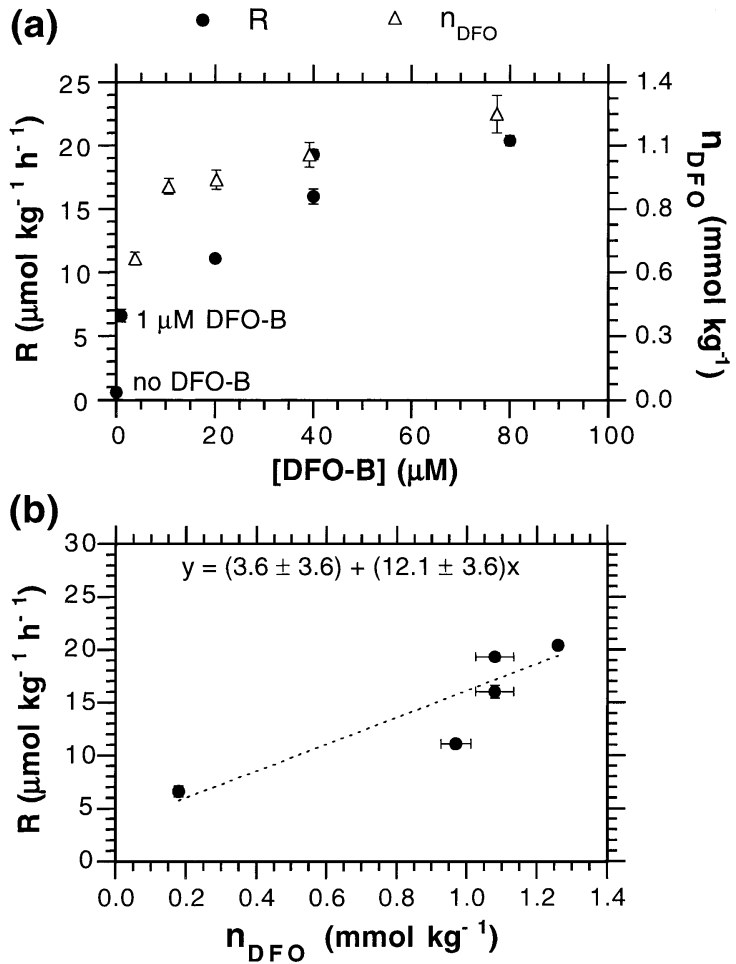

Fig. 4. (a) Mass-normalized dissolution rate of goethite and surface excess of DFO-B plotted together as a function of DFO-B solution concentration. Each dissolution rate represents a separate experiment in which steady-state $\mathrm{Fe}$ concentrations and reactor flow rates were averaged over several days to calculate $R$ as in Eq. (1). Error bars represent $\Delta R$ as in Eq. (2). Error bars for the surface excess were calculated as described in Fig. 1. Solution conditions: $10 \mathrm{mM}$ $\mathrm{NaClO}_{4}, 10 \mathrm{~g} \mathrm{l}^{-1}$ goethite, $5 \mathrm{mM}$ MOPS buffer, pH 5. (b) Plot of the dissolution rate in (a) vs. the surface excess of DFO-B. The line through the data is a least-squares fit $\left[y \equiv R\left(\mu \mathrm{mol} \mathrm{kg}{ }^{-1} \mathrm{~h}^{-1}\right)\right.$, $\left.x \equiv n\left(\mathrm{mmol} \mathrm{kg}^{-1}\right)\right]$ with $95 \%$ confidence limits indicated for the slope and $y$-intercept. The smallest surface excess value, $0.18 \mathrm{mmol}$ $\mathrm{kg}^{-1}$, which corresponds to $1 \mu \mathrm{M}$ dissolved DFO-B, was calculated using the Langmuir model in Eq. (3) with the parameters, $n_{\max }=1.23 \mathrm{mmol} \mathrm{kg}^{-1}, K_{\mathrm{ads}}=3.7 \mu \mathrm{M}$, found from analyzing the data in Fig. 1c.

plotting the dissolution rates in Fig. 4a against the surface excess and observing whether the $y$-intercept is zero [see e.g., the inset in Fig. 6 of Zinder et al. (1986)]. The result of this exercise (Fig. 4b) was a statistically significant linear relationship whose slope was $0.012 \pm 0.004 \mathrm{~h}^{-1}$, in agreement with the pseudo first-order rate coefficient calculated above. The $y$ intercept was $3.6 \pm 3.6 \mu \mathrm{mol} \mathrm{kg}{ }^{-1} \mathrm{~h}^{-1}$, which does not differ statistically from the value 0 . 


\section{ARTICLE IN PRESS}

S.-F. Cheah et al. / Chemical Geology 14168 (2003) 1-13

Table 1

Calculation of $\Delta_{\mathrm{r}} G$ [Eq. (5)] for goethite dissolution at $\mathrm{pH} 5$ in the presence of DFO-B and oxalate (solution conditions: $10 \mathrm{~g}^{-1}$ goethite, $10 \mathrm{mM} \mathrm{NaClO} 4,5 \mathrm{mM}$ buffer)

\begin{tabular}{|c|c|c|c|c|c|c|}
\hline $\begin{array}{l}{[\mathrm{DFO}-\mathrm{B}]} \\
(\mu \mathrm{M})\end{array}$ & $\begin{array}{l}{[\mathrm{Ox}]} \\
(\mu \mathrm{M})\end{array}$ & $\mathrm{pH}$ & $\begin{array}{l}\text { Flow } \\
\text { rate } \\
\left(\mathrm{ml} \mathrm{h}^{-1}\right)\end{array}$ & $\begin{array}{l}{[\mathrm{Fe}]_{\mathrm{eff}}} \\
(\mu \mathrm{M})\end{array}$ & $\begin{array}{l}R(\mu \mathrm{mol} \\
\left.\mathrm{kg}^{-1} \mathrm{~h}^{-1}\right)\end{array}$ & $\begin{array}{l}\Delta_{\mathrm{r}} G(\mathrm{~kJ} \\
\left.\mathrm{mol}^{-1}\right)\end{array}$ \\
\hline 0 & 70 & 4.90 & 2.30 & 0.18 & 0.7 & $2.3^{\mathrm{a}}$ \\
\hline 0 & 100 & 5.15 & 10.68 & 0.35 & 5.3 & 5.4 \\
\hline 0 & 200 & 4.98 & 10.40 & 1.19 & 17.9 & 1.1 \\
\hline 0 & 200 & 5.00 & 5.25 & 1.90 & 14.3 & 2.3 \\
\hline 0 & 200 & 5.00 & 1.02 & 2.21 & 3.3 & 2.6 \\
\hline 0 & 750 & 5.00 & 8.25 & 4.10 & 48.7 & -5.0 \\
\hline 0 & 750 & 5.00 & 9.36 & 4.46 & 60.1 & -4.8 \\
\hline 0 & 1250 & 5.00 & 9.37 & 5.71 & 77.2 & -7.9 \\
\hline 0 & 2000 & 5.00 & 8.46 & 10.35 & 126.2 & -9.9 \\
\hline 0 & 3000 & 5.00 & 9.42 & 9.09 & 123.5 & -13.2 \\
\hline 0 & 3000 & 5.00 & 8.89 & 9.50 & 121.8 & -13.1 \\
\hline 0 & 5000 & 5.00 & 8.52 & 14.08 & 172.9 & -15.9 \\
\hline 0 & 8000 & 5.00 & 8.97 & 12.63 & 163.3 & -19.6 \\
\hline 0 & 8000 & 5.00 & 8.85 & 12.90 & 164.6 & -19.5 \\
\hline 1 & 0 & 5.01 & 9.16 & 0.50 & 6.6 & -15.1 \\
\hline 20 & 0 & 5.11 & 10.11 & 0.80 & 11.6 & -23.0 \\
\hline 40 & 0 & 4.73 & 7.75 & 1.40 & 16.0 & -23.4 \\
\hline 40 & 0 & 5.11 & 9.70 & 1.33 & 19.3 & -23.5 \\
\hline 40 & 0 & 5.11 & 5.82 & 2.43 & 19.3 & -21.9 \\
\hline 80 & 0 & 4.96 & 2.87 & 4.93 & 20.4 & -21.9 \\
\hline 10 & 40 & 4.96 & 2.90 & 8.83 & 36.7 & -10.1 \\
\hline 20 & 40 & 5.11 & 12.47 & 2.05 & 37.0 & -20.5 \\
\hline 40 & 40 & 5.13 & 11.63 & 2.50 & 42.0 & -21.8 \\
\hline 40 & 40 & 5.24 & 9.04 & 2.96 & 38.9 & -21.4 \\
\hline 1 & 28.6 & 5.02 & 9.65 & 0.91 & 12.7 & -9.3 \\
\hline 5 & 28.6 & 5.08 & 11.97 & 2.57 & 44.3 & -15.0 \\
\hline 80 & 28.6 & 5.27 & 10.16 & 2.08 & 30.5 & -24.1 \\
\hline 40 & 10 & 5.25 & 6.35 & 2.02 & 18.4 & -22.4 \\
\hline 40 & 10 & 5.25 & 10.40 & 1.71 & 25.6 & -22.8 \\
\hline 40 & 14.3 & 5.17 & 10.55 & 1.76 & 26.8 & -22.8 \\
\hline 40 & 20 & 5.05 & 11.87 & 1.93 & 33.1 & -22.5 \\
\hline 40 & 50 & 5.09 & 2.02 & 12.11 & 35.4 & -17.2 \\
\hline 40 & 100 & 4.89 & 6.74 & 4.56 & 44.4 & -20.2 \\
\hline 40 & 142.8 & 5.22 & 9.28 & 4.22 & 56.4 & -20.4 \\
\hline
\end{tabular}

${ }^{a}$ First five values listed do not differ statistically from the value 0 .

Fig. 5 shows the mass-normalized dissolution rate of goethite at $\mathrm{pH} 5$ plotted against oxalate concentration. The overall shape of the graph is sigmoid (Fig. 5a), ultimately becoming convex at very high oxalate concentrations above $1 \mathrm{mM}$ (Fig. 5b). At oxalate concentrations below $200 \mu \mathrm{M}$, the dissolution rate is much smaller than that measured in the presence of DFO-B (Fig. 4a) at the same $\mathrm{pH}$ and ligand concentration. Moreover, the dissolution data in Fig. 5a are not congruent with the oxalate adsorption isotherm in Fig. 1a. Therefore, the dissolution rate-concentration relationship for oxalate in Fig. 5a cannot be interpreted in terms of the surface excess of oxalate, which in any case should be essentially constant over the oxalate concentration range of 100 $\mu \mathrm{M}$ to $8 \mathrm{mM}$.

Instead, it is likely that the steady-state dissolution rates plotted in Fig. 5 mainly reflect the physical removal of $\mathrm{Fe}$ from the reactor because of rapid equilibration of the solid phase with the oxalate solutions. In separate experiments at a fixed oxalate concentration of $200 \mu \mathrm{M}$, we observed a proportional increase of the dissolution rate with increasing flow rate in the reactor (Fig. 6a), and the values of $[\mathrm{Fe}]_{\mathrm{eff}}$ we measured, within their precision and that of the thermodynamic data, were not significantly different from total soluble $\mathrm{Fe}$ calculated using MINEQL+
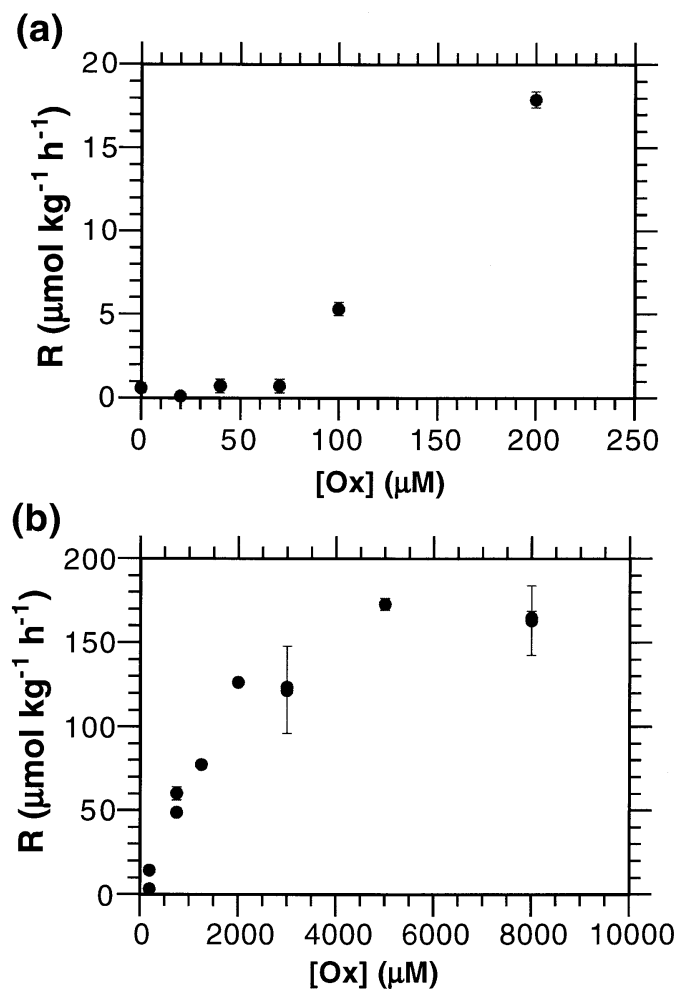

Fig. 5. Mass-normalized dissolution rate of goethite as a function of oxalate solution concentration: (a) $0-250 \mu \mathrm{M}$ range, (b) $0-8 \mathrm{mM}$ range. Solution conditions and error estimates are the same as in Fig. 4. 
centration exceeded $750 \mu \mathrm{M}$ (Fig. $6 \mathrm{~b}$ and Table 1). At oxalate concentrations above $5 \mathrm{mM}$, the dissolution rate appeared to be reaching a plateau suggesting farfrom-equilibrium conditions, as found previously for goethite dissolution (Kraemer and Hering, 1997).

Fig. 7 shows the mass-normalized dissolution rate of goethite at $\mathrm{pH} 5$ in the presence of varying concentrations of DFO-B at three fixed concentrations of oxalate (Fig. 7a), and in the presence of varying concentrations of oxalate at two fixed concentrations of DFO-B (Fig. 7b). The dissolution rate promoted by DFO-B (Fig. 7a) is approximately doubled when oxalate is present at equimolar concentrations (29 and $40 \mu \mathrm{M}$ DFO-B), whereas that in the presence of

\section{(a)}

$$
\begin{aligned}
& \square \quad \text { no Ox } \\
& \nabla \quad \text { in } 28.6 \mu \mathrm{M} \mathrm{Ox} \\
& \text { - } \quad \text { in } 40 \mu \mathrm{M} \text { Ox }
\end{aligned}
$$
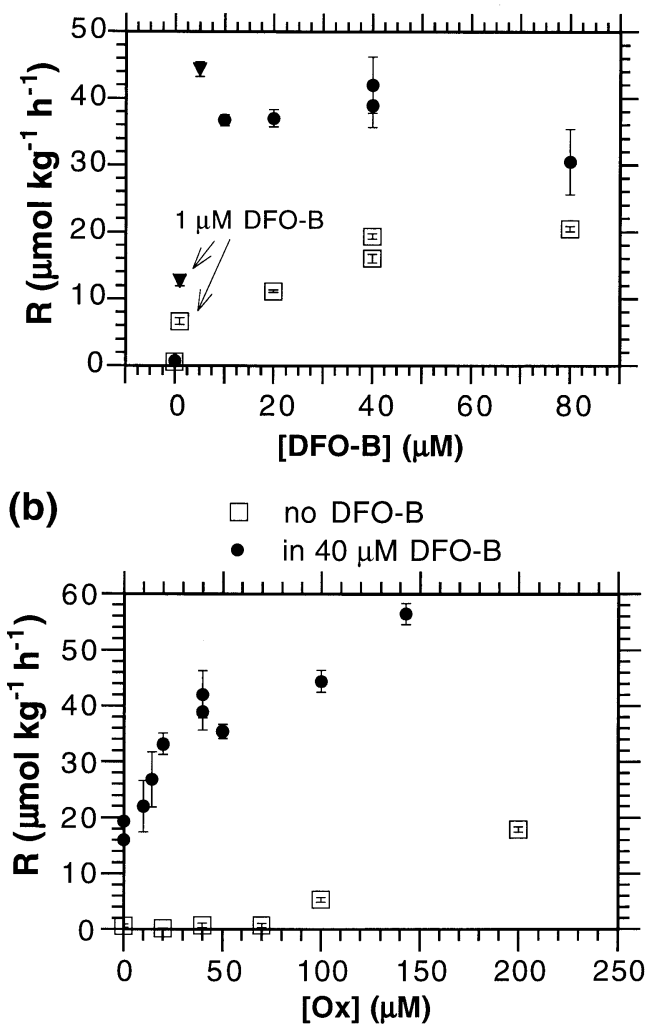

Fig. 7. Mass-normalized dissolution rate of goethite as a function of: (a) DFO-B solution concentration at three oxalate concentrations, (b) oxalate concentration at two DFO-B concentrations. Solution conditions as in Fig. 4. oxalate (Fig. 7b) is increased by more than an order of magnitude when DFO-B is present at an equimolar concentration $(40 \mu \mathrm{M}$ oxalate). At oxalate concentrations above $80 \mu \mathrm{M}$, the dissolution rate in the presence of $40 \mu \mathrm{M}$ DFO-B parallels that in the absence of DFO-B (Fig. 7b).

\subsection{Dissolution mechanisms}

The kinetics and adsorption data in Fig. 4 are consistent with a conventional model rate law for ligand-promoted dissolution (Stumm et al., 1983):

$R_{\mathrm{DFO}}=k_{\mathrm{DFO}} n_{\mathrm{DFO}}$

where $R_{\mathrm{DFO}}$ is the mass-normalized rate of steadystate dissolution [Eq. (1)], $k_{\mathrm{DFO}}=0.015 \mathrm{~h}^{-1}$ is a pseudo first-order rate coefficient, and $n_{\mathrm{DFO}}$ is the surface excess of DFO-B (Fig. 1c). The rate coefficient in Eq. (6) is, in principle, an implicit function of all variables, other than $n_{\mathrm{DFO}}$, which affect $R_{\mathrm{DFO}}$ (e.g., $\mathrm{pH}$, temperature, composition). When oxalate is present, as the kinetics data in Fig. $7 \mathrm{a}$ show, $R_{\mathrm{DFO}}$ increases by a factor of two or more. Associated with this increase is the adsorption of oxalate and a substantial desorption of DFO-B (Fig. 3). These facts suggest that, in the mixed-ligand system, the rate law in Eq. (6) becomes:

$R=k_{\mathrm{DFO}}^{\mathrm{Ox}} n_{\mathrm{DFO}}^{\mathrm{Ox}}+k_{\mathrm{Ox}}^{\mathrm{DFO}} n_{\mathrm{Ox}}^{\mathrm{DFO}}$

In order to reflect the possible influence of one ligand on the other, the two pseudo first-order rate coefficients in Eq. (7) are labeled with a subscript denoting a dissolution-promoting ligand and a superscript denoting its competitor. These rate coefficients should not be affected by ligand competition for adsorption sites because this is already taken into account in the surface excess quantities, ( $n_{\mathrm{DFO}}^{\mathrm{Ox}}$ and $n_{\mathrm{Ox}}^{\mathrm{DFO}}$ ), which are measured in the two-ligand system.

The rate law in Eq. (7) applies to parallel reactions far from equilibrium. The data in Figs. 3 and 7 a can be used to deduce a value for the pseudo first-order rate coefficient $k_{\mathrm{Ox}}^{\mathrm{DFO}}$ under the assumption that $k_{\mathrm{DFO}}^{\mathrm{Ox}}=k_{\mathrm{DFO}}$. This assumption implies that the sole effect of oxalate on the interaction between DFO-B and goethite is to reduce the surface excess of DFO-B, without altering the basic mechanism of DFO-B-promoted dissolution. On subtracting the 
(a)

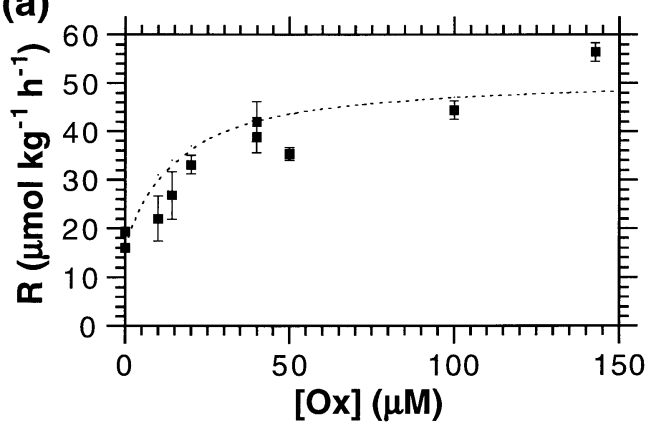

(b)

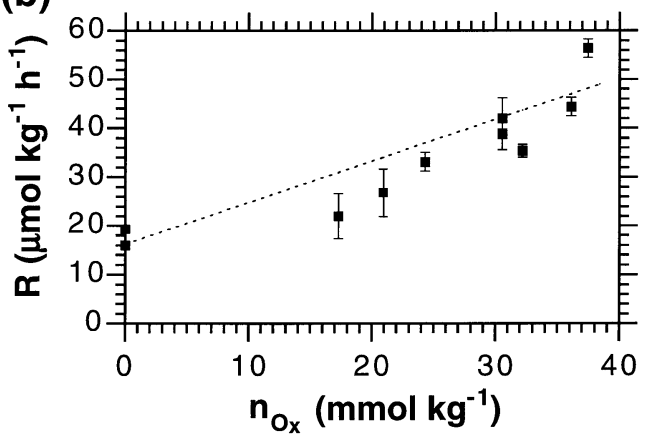

Fig. 8. Comparison between experimental ( $\boldsymbol{\square})$ and calculated (dotted) mass-normalized dissolution rates of goethite in the presence of $40 \mu \mathrm{M}$ DFO-B and varying solution concentrations of oxalate: (a) rate of dissolution vs. oxalate solution concentration, (b) rate of dissolution vs. surface excess of oxalate. The calculated rates are based on Eq. (7) with $k_{\mathrm{DFO}}^{\mathrm{Ox}}=0.015 \mathrm{~h}^{-1}$ and $k_{\mathrm{Ox}}^{\mathrm{DFO}}=0.001 \mathrm{~h}^{-1}$ (no adjustable parameters).

first term on the right side of Eq. (7) [calculated with observed values of $n_{\mathrm{DFO}}^{\text {Ox }}$ (Fig. 3a)] from the observed dissolution rate, then dividing the result by the measured values of $n_{\mathrm{OX}}^{\mathrm{DFO}}$ in Fig. $3 \mathrm{~b}$, one finds $k_{\mathrm{Ox}}^{\mathrm{DFO}} \approx 0.001 \mathrm{~h}^{-1}$ with a coefficient of variation of about $20 \%$.

A test of the rate law in Eq. (7) [with $k_{\mathrm{DFO}}^{\mathrm{Ox}}=0.015$ $\mathrm{h}^{-1}$ and $\left.k_{\mathrm{Ox}}^{\mathrm{DFO}}=0.001 \mathrm{~h}^{-1}\right]$ using the adsorption data in Fig. 2 (variable oxalate concentration, $40 \mu \mathrm{M}$ DFOB) appears plotted in two ways in Fig. 8. The dissolution rates are those measured in the presence of variable oxalate concentrations at $40 \mu \mathrm{M}$ DFO-B (Fig. 7b). It is apparent that Eq. (7) provides a reasonable quantitative description of the dissolution kinetics in a system with variable oxalate concentration and a fixed DFO-B concentration, after calibration in a system with variable DFO-B concentration and a fixed oxalate concentration.
A question may be raised as to why a far-fromequilibrium rate law [Eq. (7)] is applicable to mixed oxalate-DFO-B systems, and to a single-ligand system containing DFO-B alone [Eq. (6)], but not to a single-ligand system containing oxalate alone. For this latter system, far-from-equilibrium conditions do not obtain until the oxalate concentration exceeds $5 \mathrm{mM}$ (Fig. 6b). Insight once again can be obtained by doing a chemical affinity $\left(\Delta_{\mathrm{r}} G\right)$ calculation based on the experimental conditions for the systems containing DFO-B. As shown in Table 1, even at the lowest DFO-B concentration used in our experiments (1 $\mu \mathrm{M}), \Delta_{\mathrm{r}} G<-9 \mathrm{~kJ} \mathrm{~mol}^{-1}$, indicating undersaturation conditions. Moreover, there is no apparent dependence of the dissolution rates on $\Delta_{\mathrm{r}} G$, confirming that all of the systems in which DFO-B was present were indeed at far-from-equilibrium conditions, irrespective of whether oxalate was present.

The applicability of a far-from-equilibrium rate law [Eq. (7)] to the mixed oxalate-DFO-B system now can be elucidated further by a speciation calculation for a mixed oxalate-DFO-B solution containing dissolved $\mathrm{Fe}(\mathrm{III})$ at $\mathrm{pH} 5$. Table 3 presents the results of such a calculation, based on the first 15 reactions listed in Table 2, for a solution containing $1 \mu \mathrm{M}$ dissolved Fe(III), $40 \mu \mathrm{M}$ oxalate, and $40 \mu \mathrm{M}$ DFO$\mathrm{B}$ at $\mathrm{pH} 5$ and $10 \mathrm{mM}$ ionic strength. It is evident that all of the dissolved $\mathrm{Fe}(\mathrm{III})$ is in the soluble complex $\mathrm{Fe}(\mathrm{HDFOB})^{+}$. This same result was found after reducing the DFO-B concentration to $1 \mu \mathrm{M}$ while maintaining those of $\mathrm{Fe}(\mathrm{III})$ and oxalate at their previous values (data not shown). Therefore, so long as the concentration of DFO-B is large enough to capture all the dissolved $\mathrm{Fe}$ (III) released by goethite

Table 3

Principal speciation in an aqueous solution comprising $1 \mu \mathrm{M}$ Fe(III), $40 \mu \mathrm{M}$ DFO-B, and $40 \mu \mathrm{M}$ oxalate at $\mathrm{pH} 5$ and $10 \mathrm{mM}$ ionic strength, as calculated by MINEQL+ (Schecher and McAvoy, 1998) $)^{\mathrm{a}}$

\begin{tabular}{lccc}
\hline Species & $\begin{array}{l}\text { Concentration } \\
(\mu \mathrm{M})\end{array}$ & Species & $\begin{array}{l}\text { Concentration } \\
(\mu \mathrm{M})\end{array}$ \\
\hline $\mathrm{H}_{3}(\mathrm{HDFOB})^{+}$ & 39.0 & $\mathrm{C}_{2} \mathrm{O}_{4}^{2-}$ & 35.2 \\
$\mathrm{Fe}(\mathrm{HDFOB})^{+}$ & 1.0 & $\mathrm{HC}_{2} \mathrm{O}_{4}^{-}$ & 4.8 \\
\hline
\end{tabular}

${ }^{\mathrm{a}}$ Based on the thermodynamic data in Table 1 . In the case of 1 $\mu \mathrm{M}$ DFO-B total concentration, the concentration of $\mathrm{H}_{3}(\mathrm{HDFOB})^{+}$ drops to $4.6 \mathrm{nM}$ while all other species concentrations remain the same. 
dissolution, this ligand will wrest $\mathrm{Fe}(\mathrm{III})$ from any $\mathrm{Fe}$-oxalate complexes that may have formed, leaving an uncomplexed oxalate ligand available to react with again the goethite surface. From the perspective of the oxalate ligand, therefore, the system is indeed far from equilibrium.

The implications of Eqs. (6) and (7) for the microbial acquisition of $\mathrm{Fe}$ from goethite are most interesting. It has long been known that DFO-B, by virtue of its large affinity for $\mathrm{Fe}$, can affect the amount of bioavailable Fe [see e.g., Neilands, 1974]. Eqs. (6) and (7) illustrate two mechanisms through which this affinity can affect Fe release kinetics. Eq. (6) shows that DFO-B alone can modestly increase the rate of goethite dissolution in the absence of other ligands (ligand-promoted dissolution). However, in reality, for soils and other biologically active environments, a variety of organic ligands is always present, with oxalate being the most common (Gadd, 2000). The relevance of Eq. (7) for the microbial acquisition of $\mathrm{Fe}$ then becomes apparent. For example, the data in Figs. 5b and 7a indicate that comparable rates of goethite dissolution are to be expected in the presence of either $500 \mu \mathrm{M}$ oxalate or just $40 \mu \mathrm{M}$ oxalate combined with only 10 $\mu \mathrm{M}$ DFO-B, despite the fact that negligible dissolution occurs in the presence of $40 \mu \mathrm{M}$ oxalate alone, and rather little in the presence of $10 \mu \mathrm{M}$ DFO-B alone. Oxalate adsorption onto goethite at $40 \mu \mathrm{M}$ concentration is at about $70 \%$ of its maximal value (Fig. 1a), thereby providing a rich potential source of soluble $\mathrm{Fe}$ if the driving force for continual $\mathrm{Fe}-$ oxalate detachment from the goethite surface could somehow be increased. Adding a small concentration of predatory DFO-B ligands, which have little propensity to be lost from solution by adsorption (Fig. 1c), can serve this purpose by depleting the aqueous solution phase of $\mathrm{Fe}$-oxalate complexes, thus increasing the thermodynamic pressure for $\mathrm{Fe}$-oxalate desorption. The remarkable advantage that accrues to the microbial producer of the siderophore also can be inferred from Fig. 7a, which implies that DFO-B concentrations well in excess of $100 \mu \mathrm{M}$ would be required in order to achieve the same dissolution rate as is observed in the presence of only $10 \mu \mathrm{M}$ DFO-B, and with just enough oxalate present to adsorb abundantly while serving as prey for the siderophore.

\section{Acknowledgements}

The authors are most grateful to Kenneth Raymond for providing the sample of Desferal ${ }^{\circledR}$; to Gordon Vrdoljak for providing the transmission electron micrographs of the goethite sample; to Sabine Goldberg for providing the specific surface area measurement on the sample; and to Angela Zabel for preparation of the typescript. This research was supported in part by the Director, Office of Energy Research, Office of Basic Energy Sciences, Geosciences Program of the US Department of Energy, under Grant No. DE-FG03-96ER14667. [EO]

\section{References}

Albrecht-Gary, A.-M., Crumbliss, A.L., 1998. Coordination chemistry of siderophores: thermodynamics and kinetics of iron chelation and release. In: Sigel, A., Sigel, H. (Eds.), Iron Transport and Storage in Microorganisms, Plants, and Animals. Marcel Dekker, New York, pp. 239-327.

Biruš, M., Bradić, Z., Krznarić, G., Kujundžic, N., Pribanić, M., Wilkins, P.C., Wilkins, R.G., 1987. Kinetics of stepwise hydrolysis of ferrioxamine $B$ and of formation of diferrioxamine B in acid perchlorate solution. Inorg. Chem. 26, 1000-1005.

Cocozza, C., Tsao, C.C.G., Cheah, S.-F., Kraemer, S.M., Raymond, K.N., Miano, T.M., Sposito, G., 2001. Temperature dependence of goethite dissolution promoted by trihydroxamate siderophores. Geochim. Cosmochim. Acta 66, 431-438.

Cornell, R.M., Schwertmann, U., 1996. The Iron Oxides. VCH Publishers, Weinheim.

Crumbliss, A.L., 1991. Aqueous solution equilibrium and kinetic studies of iron siderophore and model siderophore complexes. In: Winkelmann, G. (Ed.), Handbook of Microbial Iron Chelates. CRC Press, Boca Ratón, FL, pp. 177-232.

Djafer, M., Khandal, R.K., Terce, M., 1991. Interactions between different anions and the goethite surface as seen by different methods. Colloids Surf. 54, 209-218.

Eick, M.J., Peak, J.D., Brady, W.D., 1999. The effect of oxyanions on the oxalate-promoted dissolution of goethite. Soil Sci. Soc. Am. J. 63, 1133-1141.

Gadd, G.M., 2000. Heterotrophic solubilization of metal-bearing minerals by fungi. In: Cotter-Howells, J.D., Campbell, L.S., Valsami-Jones, E., Batchelder, M. (Eds.), Environmental Mineralogy. The Mineralogical Society, London, pp. 57-75.

Holmén, B.A., Casey, W.H., 1996, 1998. Hydroxamate ligands, surface chemistry, and the mechanism of ligand-promoted dissolution of goethite $[\alpha-\mathrm{FeOOH}(\mathrm{s})]$. Geochim. Cosmochim. Acta 60, 4403-4415; 62, 726.

Kalinowski, B.E., Liermann, L.J., Givens, S., Brantley, S.L., 2000. Rates of bacteria-promoted solubilization of Fe from minerals: a review of problems and approaches. Chem. Geol. $169,357-370$. 
Kraemer, S.M., Hering, J.G., 1997. Influence of solution saturation state on the kinetics of ligand-controlled dissolution of oxide phases. Geochim. Cosmochim. Acta 61, 2855-2866.

Kraemer, S.M., Cheah, S.-F., Zapf, R., Xu, J., Raymond, K.N., Sposito, G., 1999. Effect of hydroxamate siderophores on $\mathrm{Pb}(\mathrm{II})$ adsorption and $\mathrm{Fe}$ release by goethite. Geochim. Cosmochim. Acta 63, 3003-3008.

Lasaga, A.C., 1998. Kinetic Theory in the Earth Sciences. Princeton Univ. Press, Princeton, NJ.

Liermann, L.J., Kalinowski, B.E., Brantley, S.L., Ferry, J.G., 2000. Role of bacterial siderophores in dissolution of hornblende. Geochim. Cosmochim. Acta 64, 587-602.

Martell, A.E., Smith, R.M., Motekaitis, R.J., 1998. Critically Selected Stability Constants of Metal Complexes Database. NIST, Gaithersburg, MD.

Mesuere, K., Fish, W., 1992. Chromate and oxalate adsorption on goethite: 1. Calibration of surface complexation models. Environ. Sci. Technol. 26, 2357-2364.

Nagy, K.L., Blum, A.E., Lasaga, A.C., 1991. Dissolution and precipitation kinetics of kaolinite at $80{ }^{\circ} \mathrm{C}$ and $\mathrm{pH}$ 3: the dependence on solution saturation state. Am. J. Sci. 291, 649-686.

Neilands, J.B., 1974. Iron and its role in microbial physiology. In: Neilands, J.B. (Ed.), Microbial Iron Metabolism. Academic Press, New York, pp. 3-34.

Parker, V.B., Khodakovskii, I.L., 1995. Thermodynamic properties of the aqueous ions $(2+$ and $3+)$ of iron and the key compounds of iron. J. Phys. Chem. Ref. Data 24, 1699-1745.

Robie, R.A., Hemingway, B.S., 1995. Thermodynamic Properties of Minerals and Related Substances at $298.15 \mathrm{~K}$ and 1 Bar $\left(10^{5}\right.$ Pascals) Pressure and Higher Temperatures. U.S. Geol. Surv. Bull. 2131. U.S. Government Printing Office, Washington, DC. Schecher, W.D., McAvoy, D.C., 1998. MINEQL+, A Chemical
Equilibrium Modeling System. Environmental Research Software, Hallowell, ME.

Schwertmann, U., Cornell, R.M., 1991. Iron Oxides in the Laboratory. VCH Publishers, Weinheim.

Soares, H.M.V.M., Conde, P.C.F.L., Almeida, A.A.N., Vasconcelos, M.T.S.D., 1999. Evaluation of $n$-substituted aminosulfonic acid buffer with a morpholino ring for cadmium and lead speciation studies by electroanalytical techniques. Anal. Chim. Acta 394, 325-335.

Solinas, V., 1994. Cation effects on the adsorption of desferrioxamine B (DFOB) by humic acid. In: Senesi, N., Miano, T.M. (Eds.), Humic Substances in the Global Environment and Implications on Human Health. Elsevier, Amsterdam, pp. $1183-1188$.

Sposito, G., 1989. The Chemistry of Soils. Oxford Univ. Press, New York.

Sposito, G., 1998. On points of zero charge. Environ. Sci. Technol. $32,2815-2819$.

Stumm, W., Furrer, G., Kunz, B., 1983. The role of surface coordination in precipitation and dissolution of mineral phases. Croat. Chem. Acta 56, 593-611.

Watteau, F., Berthelin, J., 1994. Microbial dissolution of iron and aluminum from soil minerals: efficiency and specificity of hydroxamate siderophores compared to aliphatic acids. Eur. J. Soil Biol. 30, 1-9.

Yu, Q., Kandegedara, A., Xu, Y., Rorabacher, D.B., 1997. Avoiding interferences from Good's buffers: a contiguous series of noncomplexing tertiary amine buffers covering the entire range of pH 3-11. Anal. Biochem. 253, 50-56.

Zinder, B., Furrer, G., Stumm, W., 1986. The coordination chemistry of weathering: II. Dissolution of Fe(III) oxides. Geochim. Cosmochim. Acta 50, 1861-1869. 